\title{
The Choice of Gender Roles and the Perceptions of Gender Violence in Regions of Armenia
}

\author{
Anahit Manasyan \\ American University of Armenia, Yerevan, Armenia
}

\begin{abstract}
This article describes results of the fieldwork study concerning the reasons of gender roles' choice and the possible violence in Armenian families that occur from the gender roles. I have completed field study encompassing nine, out of 11, administrative regions of Armenia. The purpose of this study is to understand the perception level of domestic violence, child abuse and society's approach to the latter by conducting quantitative survey. These findings may be useful for the experts specialized in the gender violence and working on adapting the value system of EU countries in Armenia.
\end{abstract}

Keywords: perceptions, gender roles, violence, unconscious rape, value system

\section{Introduction}

Domestic violence and child abuse are sizeable concerns of current administration of the Republic of Armenia. Seyran Ohanyan, the Minister of Defense of RA, has mentioned that the massive violence and criminal cases in Armenian army were the results of domestic violence and child abuse. Moreover, several gynecologists announced during the press conference hold on the 14 of April 2011 that each second virgin became a victim of "unintentional rape", i.e. when a lack of sexual educations results in severe injuries of women's sexual organs. Several experts specialized in this field, decided to develop a preventive project by cooperating with the European and American experts. One of the tasks of that project was defining "domestic violence and abuse" terms. A conflict of understanding occurred between local and international experts. It became crucial to find out the perceptions of Armenians about domestic violence and child abuse. This is necessary to be able to analyze the existing mechanisms and education methodology for preventing the domestic violence and child abuse in Armenia.

The reason for conducting this study was to understand the Armenian society's approach towards the above mentioned topic and to define the term "violence" by taking into consideration the entire range of their personal perceptions.

This work researched and analyzed the Armenian people's life style, gender roles and the communication between men and women, the reasons and motivations of the gender roles' choice.

This research is conducted by me and with my personal funds (without any additional funding). The research methodology was discussed and approved by a clinical psychologist, and state expert on child abuse and domestic violence.

\footnotetext{
Anahit Manasyan, Ph.D. in Economics, College of Science and Engineering, American University of Armenia.

Correspondence concerning this article should be addressed to Anahit Manasyan, 40 Saryan str. Apt, 52, 0002 Yerevan, Republic of Armenia.
} 
The literature review discusses recent studies that performed the reasons and motivations of gender roles' choice, and the main factors creating family violence and child abuse.

Among the findings, I would like to emphasize two major ones. First, main reasons and motivations of gender roles' choice, i.e. what are the mostly chosen roles by men and women, as well as why are they chosen. Second, the definition and the perception of the term "violence", this part also includes the moral satisfaction from gender dialogue (dialogue also means relationship). I also focused on gender role attitudes and violence because of the intensive modifications in gender ideologies in recent decades. Moreover, I think that these changes may affect the families and, consequently, the society.

\section{Literature Review}

Gender refers to the "socially learned behaviors and expectations associated with being female or male" (Davidson/Moore Study Guide, 16). Gender is the concept of maleness or femaleness, or, as Davidson/Moore state, gender is "a cultural and psychological concept reflecting one's subjective feelings of femaleness or maleness. A person's sex, in contrast, is determined by biological factors, genital organs, or genes. In other words, gender is constructed by people, not by biology?” (Davidson and Moore, 48).

In other words, gender roles are "traits, behaviors, and attitudes socially prescribed for women and men in a given culture" (Davidson/Moore, 48). Gender roles are "social scripts that define how males and females are supposed to act" (Skolnick, 1992).

According to another definition, a gender role is a set of social and behavioral norms that are generally considered appropriate for either a man or a woman in a social or interpersonal relationship. There are differences of opinion as to which observed differences in behavior and personality between genders are entirely due to innate personality of the person and which are due to cultural or social factors, and are therefore the product of socialization, or to what extent gender differences are due to biological and physiological differences (World Health Organization, Retrieved 2009). Gender roles differ according to cultural-historical context, and while most cultures express two genders, some express more (Emmons, 1966).

Gender roles are defined by the socio-cultural norms of any society. In most of the societies the family systems are based on the gender roles and it is the pre-designed gender roles that help members of the family to run the family with bound responsibilities. Any disturbance in the gender role aspect may affect the smooth functioning of the easy-going of any family (Ickes, 1993).

When the issue is one of physical and sexual attraction, we are ruled by instincts that have their roots deep in the past. However, when the issue is one of trying to establish a nonexploitive, equal-partner relationship, we find these old instincts troublesome and aspire to be ruled by our ideals instead (Ickes, 1993).

I believe society plays an immense role in the construction of individual gender roles and in turn our identity. This is not to say that society has complete control over this construction. Evidence shows that biological sex-linked factors involving hormones like testosterone do contribute to the formation of gender. Despite the reinforcement of the domestic ideal, women aspired to continue working after the post-war era. This reveals what might be the dominant paradox connecting the cultural domestic ideal to the reality of women's lives. "In an era marked by the quiescence of organized feminism and the celebration of domesticity by public figures and popular culture, increasing numbers of women were seeking employment outside the home” (Meyerowitz, 1994). 
Friedan alleged that magazines did not passively participate in enforcing these gender roles, but were in fact an active force behind the creation of what she termed the "feminine monster." She claimed that the manufacturing sector "had decided to make women better consumers of home products by reinforcing and rewarding the concept of women's total fulfillment through the role of housewife and mother" (Friedan, 1963).

Different behaviors exhibited by men and women are thought to accord with socially ascribed gender roles; behavior is not biologically determined but is conditioned by normative beliefs about what is appropriate for men and women and by differences in skills and attitudes that have developed from enacting these ascribed roles (Eagly \& Wood, 1991).

Feminists and gender theorists have pushed to de-essentialize and delink biological sex and socially constructed gender, and to underscore that masculinities are produced and reproduced by individual men with available resources while also being influenced by dominant hegemonic masculinities (Connell, 2005).

Such justifications do not find support among evolutionary psychologists, who stress that very few of the characteristics required to perform most tasks are gender specific (though behavioral traits once had an evolutionary purpose, most are not directly motivating), and that human behavior displays tremendous variation, largely due to diversities in social and cultural environments (Sork, 1997).

However, it is possible to accept the evolutionary basis for much of human behavior while rejecting biological determinism and gender inequality. Once it becomes clear that biological processes are not immutable (and do not equate with genetics) and that great variation exists due to the diversity of social and environmental factors to which humans are subjected, feminism and evolutionary psychology arrive at the same place: the problem lies not with the biology of individuals but with the environments in which they find themselves and to which they must adapt. The answer to changing behavior lies in changing environments. Thus, the same conclusion is arrived through a different lens (Holly Johnson, 2012).

During the war years the war itself served as both a context for appeals for postwar social improvements and a new primacy by which those appeals were judged. Thus, while some emphasis was put on ending some of the worst practices of racism and sexism it was done from a framework in which primacy was given to war effort. It was a framework that valorized the new subjectivity of the warrior (which served to recast women as being of the "home-front"). The term "Rosie the Rivetor" neatly captures both the unusual character of women at work, and especially in certain classes of industrial work, while reminding us that women's place is 'normally' in the home (Mary Runte; Albert J. Mills "The Cold War, Feminism, and the Ideation of the American Family”; paper for Presentation at Critical Management Studies Conference 3 "Cold War Stream”, University of Lancaster, July 2003).

This demarcation was buttressed by the war effort, which relied upon the mythology of the American warrior supported by the female helpmate awaiting his return. The feminine, while revealed in the wartime and post-war discourse as a figurehead of Americanism, remains less valued than the masculine which is revealed as the core of the capitalist project - the foundation for American culture without which the entire structure would collapse (Mary Runte et al., 2003).

This sense of personal empowerment had the potential to erode the rigid lines between work and family discourses for some women. This potentiality remained unrealized, however, as it encountered the discourses of the Cold War era, which emerged from World War II. The development of the "feminine mystique" (Friedan, 1963), "Our entire manpower problem is most acutely a problem of womanpower” (Business Week, September, 1943). 
Previously established notices of masculinity were also reinforced by the war effort. Although the female was portrayed as the helpmate, the primary responsibility for the war effort was placed on the male. During the war, the government, the military and the communications industry constructed women as objects of male obligation. Men were to fight, not as an obligation of citizenship, but to protect their sisters, wives, mothers and daughters (Westbrook, 1990).

The second effect of the propaganda campaign, however, was not anticipated. Opposition to female labour was curtailed by the discourse of women as helpmates, but a discourse of capability was also necessary to mobilize women once opposition was dispelled. The (albeit temporary) movement of women into male dominated industries hinged upon the reinforcement of the female worker as both physically and intellectually capable of making the necessary contribution. Rosie was portrayed as a highly feminized figure, and she also displayed muscled biceps and strength. "You can do this" was the second message of the propaganda campaign: "they left their kitchens for (aircraft production) and other industries, learned quickly and were wonderfully successful” (Weatherford, 1990).

Women's personal gains were to be challenged by absorption into the "feminine mystique" (Friedan, 1963). An examination of the discourses of masculinity and femininity under cold war influences, such as McCarthyism, demonstrates the entrenchment but also the reinvention of gendered boundaries between work and home (Mary Runte et al., 2003).

Traditional concepts of femininity were emphasized to develop more "manliness through contrast" (Grant, 1994).

The World War II opened up tensions between traditional notions of women as wives and mothers and the realities of wartime work experienced by large numbers of women. The working and intellectual women began suspect, and enemy of the status quo (Mary Runte et al., July 2003).

First, it indicates that it's no longer women alone who are demanding changes in society's accommodation to the family; men brought about this change, they were the ones to stand up for their rights as shopping fathers with wet babies and they deserve to be commended for it (Walker, 1999).

What is notable is that upscale fathers now regard the inability to diaper their babies as a deprivation. These men could well become that generation of male lawyers and doctors and corporate executives who will actually pay attention to demands for parental leaves and convenient, affordable day care (Brown, 1987).

But the truth must be heard. Being equal in worth, or value, is not the same as being identical, interchangeable beings. Men and women may be capable of doing many of the same things, but that doesn't mean they want to. That we don't have more female CEOs or stay-at-home dads proves this in spades. Unless, of course, you're beholden to feminism. In that case, you'll believe the above is evidence of discrimination. You'll believe what feminists taught you to believe: that gender is a social construct (Venker, 2013).

Evidence that socioeconomic factors may affect family gender role attitudes includes findings that women and men who have higher educational attainment and income express more egalitarian gender role orientations (Crompton \& Lyonette, 2005; Lackey, 1989).

As noted, children learn about gender appropriate behaviors by observing the behaviors of their parents. Over time, their knowledge consolidates to form cognitive schema which later organizes new knowledge about gender and channel gendered behaviors (Martin \& Ruble, 2004).

"Perhaps no single facet of human behavior in the 20th century has more influenced marriages and families than have changing gender roles” (Kenneth Davidson and Nelwyn Moore, Marriage and Family: Change and Continuity, 48). 
Most married couples develop a shared understanding of who does what in their relationship. It is a sometimes unspoken recognition of an inevitable division of labor and responsibilities. The current, commonly agreed, "politically correct" plan for marriage is an equal sharing of chores and other duties; but this plan is not followed now any more than it has been throughout history (Neuman, 2013).

In case if the roles are exactly defined in family and society, what can become the reason for the gender violence? There are several researches on this topic too.

Physical aggression, which demonstrates large and consistent sex differences, is an exception, although anthropological evidence of wide variation in the use of violence to construct masculinity over time and across cultures is taken as further indication that male violence is dictated by social circumstances (Hyde, 2005; Sanday, 1981, 2008).

In fact, many express unambiguous hostility, claiming that an evolutionary framework is "inherently misogynistic and provides a justification for the oppression of women” (Tang-Martinez, 1997, p. 116).

After decades of social research, it is now an accepted truth that male sexual jealousy and possessiveness are leading correlates of lethal and nonlethal violence against female intimate partners cross-culturally, and that attempts to control female partners often exist independently of physical or sexual violence (Campbell, 1992; Daly \& Wilson, 1988; Johnson, Ollus, \& Nevala, 2008; Krahé, Bieneck, \& Moller, 2005; Stark, 2007).

Furthermore, it suggests that an exploration of evolutionary causes might be fruitful to explain why men manifest sexual jealousy through attempts to control female partners in ways that women do not, why violence is primarily an activity of males, and how most acts of male violence-including violence against female partners - concern competition among men for respect and status (Wilson \& Daly, 1985).

Of course, women also exhibit jealousy when their mates turn their attention to other women, but the physiological and behavioral arousal is qualitatively different: jealousy of women toward male adulterers is more often linked to the potential loss of economic resources, attention, and emotional commitment, while male sexual jealousy is more often focused on the sexual act and the fear that female partners will produce another man's child (Daly, Wilson, \& Weghorst, 1982).

In short, evolutionary psychologists assert that human behavior has evolved to be extremely adaptable, so that fitness can be maximized in a wide variety of environments. Thus, while evolved psychological processes explain sources of conflict and motivations for using violence, social influences are possibly even more important for understanding when those conflicts and motivations will be acted upon (Sork, 1997, p. 107). One of such cases can be the serotonin level. This is the persuasive point for socio structural theorists-that biological does not equate with genetic. Whereas genetics are fixed and inherited, biological conditions such as serotonin levels (among other things) can be altered by environmental factors that, in turn, can affect behaviors. Serotonin is correlated with risk taking and violence, and men (and other primates) who are lowest on the social status hierarchy have been found to have lower levels than those who are higher up. However, once social status rises as a result of social cues and opportunities, serotonin levels also rise while risk taking and aggression declines (Edwards \& Kravitz, 1997).

Going beyond intimate partners as the targets of violence, supposed "senseless" killings can be understood as the defense of male honor in social contexts where a man's reputation and saving face depends on the maintenance of a credible threat of violence (Daly \& Wilson, 1988, p. 128). At that time, small-scale qualitative studies with women in shelters and studies of men in behavioral change programs following conviction for partner violence were beginning to show that, in addition to physical and sexual violence, men frequently used 
psychological abuse and tactics to control and restrict the behavior of women, such as taking keys and vehicles to isolate them and prohibiting access to money and contact with outsiders (R. E. Dobash \& R. P. Dobash, 1979; R. P. Dobash, R. E. Dobash, Cavanagh, \& Lewis, 2000). Thus the gender roles' choice and gender violence have direct relationship, and the number of crime cases differs from country to country depending on the social status of men and women.

\section{Research Question}

It is important to find out the first victims of domestic violence and to define who becomes a victim during the "gender dialogue" in Armenian society? Who and what factors are responsible for creating domestic violence? Does the social role of a person play a crucial role in domestic violence prevention?

\section{Hypothesis}

The main violence translators and/or transformers are women, as their essential roles in society are nursing, upbringing children, and educating.

\section{Methodology}

Random sampling was taken from two cities and/or rural communities of each administrative region. Factors as marital status and having children were considered. Participants were from different age groups. Both, individual and group interviews have been conducted.

The first block concerned first of all their childhood: What was his/her fairy tale and who was his/her beloved hero?; why did he/she love that hero?; did he/she tell stories to his/her children?; how does he/she influence forming children's personalities and character traits?; if the child(ren) does not obey to his/her will, how does he/she prevent the child(ren) actions?; were the same preventive measures applied by his/her parents in childhood?

Each of the above mentioned questions has psychological importance. Below are presented their explanations:

(1) What was his/her fairy tale and who was his/her beloved hero?- - this question expresses the situation that she/he would like to appear in their life and the hero is the symbol of an ideal personality that he/she would like to be like;

(2) Why did he/she love that hero?- this question helps to find out the essential features of the participants' value system;

(3) Does he/she tell stories to his/her children?-this question performs the methodology of transferring the values and upbringing the next generation;

The second block concerned the education that the interviewee gave to his/her child(ren): How does he/she influence upbringing children's personality and character traits?- the participants tell about the duties done by them for influencing child(ren);

If the child(ren) does not obey to his/her will, how does he/she prevent the child(ren) actions?-this question provokes the possible violent act, i.e. the participant uses the strongest preventive actions-beating, punishing and/or ignoring;

The third block concerned his/her personal behavior, i.e. he/she is either translator or transformer of the culture that carried his/her ancestors: Had the same preventive measures been applied by his/her parents in 
childhood?- - this question shows the regenerating process of informal education methodology which is very important for finding out the thread of family violence and child abuse in Armenian families.

All the interviews were registered, then the answers were inserted in the questionnaires and the results were analyzed with an expert psychologist. The total number of female participants was 75 and male participants 64, i.e. 139 interviewees.

\section{Data}

Some interesting findings came up during the data analysis. The characters of the heroes described by female participants approximately resembled each other. The beloved heroes were happily married, they felt appreciated in their families and society, and were respected by their wives/husbands. Also, the mentioned heroes are well recognized in society thanks to their encouraging and benevolent commitments.

The lifestyle of those heroes resembled too, even if the tales mentioned by the participants were different. These heroes were from modest families, lived in poor conditions, everyday did the same work in the fields. Once a magician appeared to those heroes and gave a special thing (advice, magic wand, and small stone) that symbolized the divine wisdom and would change the reality.

The reason of the heroes' preference was the social appreciation, i.e. they were recognized and respected personalities, honored by society. Moreover, they were very kind and willing servants.

The story telling for the next generation seems vague. Even though parents loved storytelling in childhood, they considered it useless activity for their children. Fifty-seven female interviewees did not tell any story to the child, 11 of them sometimes tell, and only seven of them tell fairy tales/stories to their children every evening before sleeping. This point makes us wonder how children's personalities are being formed in the cities and in the rural communities of Armenia. Most of educated women live in cities and interviewees from the cities were fond of storytelling. In rural communities the image was very different. Daily life is full of problems and the elementary comfort is absent. The female participants living in rural communities work at creating comfort (cleaning house, making bed, cooking etc.), $63 \%$ of their husbands left for other countries, in order to seek a job. The 52\% of the female participants had sons of school age that did not attend any educational institution. They became a "tool" for their mothers and were involved in daily hard work. The methodology of upbringing the children by telling stories/fairy tales were forgotten. It may sound surprising if these boys are described as victims of their socially unrealized mothers. Another finding was that both female and male participants thought that beating a child, showing ignorant behavior, and making devastating expressions are forms of punishment and discipline. They did not realize that all the mentioned measures are considered child abuse. The preventive measures for the active children, whose activeness is considered as non-obedience in most cases, remain the violent and abusive acts. While discussing the "punishment" with participants, they told that girls were calm, manageable and obedient, but boys were noisy, hyperactive and unmanageable. This was the reason of becoming the object of violence and abuse.

When the participants were asked about other preventive measures, the 10 female participants living in the cities told that they tried to explain the children the possible consequences of their acts. The rest 65 female interviewees thought that the best way to form children and to preventive dangerous actions was the punishment (beating, ignorance and humiliation of dignity and pride by using devastating expressions). The male participants without any exception told that the beating was not acceptable, but they used to beat their children, as it was the best way to control the child and they were punished the same way in their childhood. 
The next step that is necessary is to draw parallels between the results of survey with the real life of participants, i.e. the reflection of fairy tales in their life (social status, role and functions).

The 10 female participants living in the cities were educated; moreover two of them even had Ph.D. Their life was "constructed" by themselves (the magic wand for them was the education). Three of participants were successful businessmen; they chose these roles, because they decided to share the responsibility with their husbands and to be equal with them. According to the results of the urban female participants' interviews, society has no influence on their decision making and role choice. They wanted to be equal for educating and upbringing better children than their parents, also, they took initiatives in developing legislative norms and participated in social activities by advocating rights of various vulnerable groups. They look like their beloved heroes from fairy tales, and could take magic wand for making miracles and changing the reality. Their ambition was to give their children the best education. It is crucially important to mention that during the interview some participants came with their children, and even if they were very active kids, at least they were not aggressive. The reason was obvious: the education and upbringing was without any punishment.

The rest 65 female participants living in the rural communities either finished high school or left it from the middle school, only three participants had graduated technical college. Their life was an "annoying routine", i.e. the same house work, same soap operas and the same problems, nothing could be changed. These women waited for "the miracle" that "a hero with a magic wand" would come and change the life in the community. Even if they were given opportunity to change their life (for example the Minister of Emergency Situations launched a project for training female rescuers in the rural communities that would receive monthly salary approximately 450 USD that was really very high rate and that could change their life. Unfortunately, this project was failed, because the women preferred comfortable life they did not want to take risks and to share responsibilities, it was much better to have routine life, but not to take responsibilities). How did they form their children? The big question and the urgent problem are needed the societies' attention.

The children were considered as manpower. Mothers had decided the roles of their children. Fifty-four of female participants decided that their children would not continue the education, because the financial means of the family was not sufficient, as well as the educated children were inclined leaving rural communities and the family would lose its manpower. Thirty-nine participants did not allow their sons to go to school. Boys helped their mothers in daily work. The rights of receiving education were violated by the mothers (the first case of violence). These children learned from their ancestors how to organize the farm work and in most cases they were not successful, because they did not know many nuances in farming (lack of education). Fifteen participants saw their daughters as future housewives and nothing more. Their daughters were exploited in hard house work.

Another way of abuse in rural communities is keeping children in fear and beating for disciplining. When asked, if they considered child beating a violent and abusive behavior, all the participants rejected this definition. Moreover, when they were told that the children had right of education, in some cases the response was just a justification of their opinion or careless neglect.

Male participants live by stereotypes. They thought that the heroic acts could be done by men, (participating in decision making of community, become a soldier etc.) because women were considered as powerless objects. They needed women just for having a partner for continuing generation and for creating comfort at home, i.e. they did not trust women as their real partners. Male participants were involved in making money for family. Only three urban fathers were actively involved in the education and upbringing of their 
children, the rest thought that it was not their duty. One of the male participants honestly told that he regularly beat his wife, because she abused him by demanding more money. The other participants confirmed the fact that Armenian women had become very demanding in financial issues. When they asked how many times they experienced their wives abusive behavior, they didn't answer.

What kind of generation is being formed now? In few words it may be described as following: aggressive, nervous, and stressful. The communication between children is full of dangerous acts (activeness differs from aggressiveness; the Armenian children are aggressive and active, for example they play and shout, but during the play they can beat and hurt each other).

It is already obvious that choice of gender role in Armenia creates violence in families. The "punished child" performs his/her habits in his own family (during sexual relationship), work place and even in the army (Armenian army every year has various crime cases caused by domestic violence and abuse in childhood).

\section{Discussion}

According to Alina Poghosyan, there are four discourses outlined in the research about the "The Gender discourse and the Gender Policy Perspectives in Armenia”: Conservative, nationalistic, equality, and western discourses (Poghosyan, 2012).

During my research, I found out similar orientations. Below are presented several interviews as life stories that reflect each discourse.

Conservative discourse was modeled mainly in the farther rural communities. Either men or women rejected the modern perceptions about the domestic violence and gender roles. In the frames of this discourse the traditional cultural stereotypes remain unchangeable. The role of women is decided by the elders of the family, which means to keep the image of traditional Armenian women as a nursing, upbringing, and educating person (but not personality). The happiness of women is in transforming these stereotypes, otherwise she can be "punished". For example, A. Sarafyan, 42 year old grandmother, was one of the interviewees, she was from Tsovagyugh ${ }^{1}$, she told that women were only home keepers; she did not want to accept that women had to work hard for nursing the family. Moreover, her daughters in law were not allowed to work outside of home as well. According to her, women must think only about the children and housework.

The methods of educating the children were indescribable, she beat her sons in childhood and thought that the best way for expressing the love and preventing them from danger was the beating.

Nationalistic discourse was obvious in each part of the country. In the frames of the latter, the interviewees thought that women had to be considered as a mother (but not just a women, as they could not even describe what should do the woman in society), who was responsible for family Morales. The propagators of this model were from 40 up to 55 years old men and women.

A. Movsisyan, 42 year old father of three daughters, agronomist from Artik $^{2}$, his main mission was to marry all three daughters with wealthy men from good families. He did not accept any other role of women besides the role of mother. The method of upbringing the children was beating, for hit it as normal to beat the wife and the daughters, but never the mother as she was a "holy person".

\footnotetext{
${ }^{1}$ Tsovagyugh is a rural community in Gegharkunik marz (administrative district in Armenia approximately $75 \mathrm{~km}$ far from Yerevan).

${ }^{2}$ Artik is a rural community in Shirak marz (administrative district in Armenia approximately $67 \mathrm{~km}$ far from Yerevan).
} 
Equality discourse is typical for people from 35 up to 39. They think that everyone should be given equal rights and opportunities. But in this discussion, it was found out a trap, i.e., there are some spheres that women do not want to enter, for example military forces, construction, transport, and police (especially traffic police). Also, there are some spheres that men do not trust women and create many obstacles for preventing their entrance, for example politics (parliament, ministries etc.). It is possible to find out the main psychological problems of Armenian society in the frames of this discourse. For example, K. Hakobyan, 48 year old woman grew up in Yerevan, ex deputy minister, thought that women did not have to take so many responsibilities, as she remains the main child guardian and the military service would be too much for her. Moreover, when she was asked how the women would make significant decisions concerning the state if she did not get the remotest conception about the state security, she replied that such decisions could be made by holding a consultation on such issues with male politicians. Some of the interviewees that correspond to this group told that the domestic violence is directly connected with the women role. As much the woman is active in society, as less the possibility of being violated by the husband.

Western discourse develops among the young generation living in Capital. The female interviewees from Yerevan were ready to serve in military forces, to do any kind of work. L. Hambardzumyan 29 year old civil servant working in City Hall of Yerevan, told a very nice story about her fairy tale "Anahit" . She was so much impressed with the heroine strong behavior that decided to be like Anahit. Moreover, she was ready to educate her future child (she was pregnant) as a brave and smart girl.

One more discourse I discovered during this research and decided to call as a religious discourse. The former concerned mainly about the spiritual behavior of both men and women. This type of discourse was obvious even in the big cities of Armenia. The term- "gender" is considered like a nonsense that is associated with hidden homosexuality. In the frames of religious discourse, the choice of men's and women's role is free, but it is preferred to see women working in so called safe environment. They are spirits of family and have to be obedient to their husbands, but at the same time idolized by all the members of family.

K. Harutyunyan, 32 years old mother and her husband A. Harutyunyan, 35 years old farmer, lived in Goris ${ }^{4}$, she helped her husband in farming by doing little part of job. She did not want to work in cow house, as she was accepted by herself as an "idol woman" and had to be treated carefully by husband. That was her rule in family and the husband added with smile that the best man had to be afraid of his wife, otherwise the family would collapse. This couple thought that the best preventive measures in upbringing were ignorance and deprivation.

It should be noted that the young generation will be able to change the society perceptions about the violence and the gender role choice. Also, it is expected that somehow women will enter all the spheres of activity and will be ready to share all the responsibilities with men. In this case, the Armenian women will have a new image. They will transform from a nursing, upbringing, and educating person into a decision-making and responsibility-taking person. Only then it is pretended that the domestic violence will decrease in Armenia.

\section{Limitations}

I did not research sexual relationship and intimate communication between spouses, as these issues are

\footnotetext{
3 "Anahit" is a tale written by Armenian writer-Gh. Aghayan, where Anahit was a strong queen that could deliberate her husband from captivity.

${ }^{4}$ Goris city in Syunik marz (administrative district in Armenia approximately $173 \mathrm{~km}$ far from Yerevan).
} 
considered very private in Armenian society.

Majority of gynecologists and sexual pathologists confirm that even in therapeutic cases Armenian couples (couple refers both to spouses and partners) are much closed. I think that in near future a methodology should be developed for studying intimate life of couples, since it has an influence on domestic violence.

\section{Conclusion}

The research results show that the choice of gender roles has direct influence on the family violence. Armenian women are not considered as trustful partners and are not involved in decision making either in families or in state institutions. The abusive and violent methodologies of children's education and upbringing are also developed by women. The first victims of these phenomena are boys and later they perform the "developed abusive and violent" behavior in their own families, i.e. the further victims are women. Moreover, in most cases abusive behavior towards children is considered an effective way of punishment and discipline. This situation will remain the same until women change their social roles. They have to take responsibility and share all the duties with men by carrying possible works and functions, according to their physical capacities. The gradual change is obvious mainly in urban life where women have more duties than house work. Consequently, the rate of violence in cities is less in comparison with the rural communities (urban women know their rights and in the case of violence they know how to protect themselves). This change happened after Karabagh war that took place from February 1988 to May 1994. The young generation that was born in 1990s will be able to change the society perceptions about the violence and the gender role choice. Perhaps, soon the Armenian society will have new image of women who are going to be decision makers and responsibility takers.

\section{Acknowledgements}

This research is conducted by me and with my personal funds (without any additional funding). Due to extraordinary sensitivity of research questions, prior to interviewing informants (mostly women and children), I had consulted with Elina Asriyan, clinical psychologist in Armenia and instructor in the Chair of Psychology of the Yerevan State University, and Ines Poghosyan, expert on child abuse and domestic violence.

\section{References}

Brown, V. (1987). Milestone in history of U.S. Gender roles, June 13, 1987.

Business Week, September, 1943.

Campbell, J. C. (1992). “If I can’t have you, no one can”: Power and control in homicide of female partners. In J. Radford and D.

E. H. Russell (Eds.), Femicide: The politics of woman killing (pp. 99-113). New York, NY: Twayne.

Connell, R. W. (2005). Masculinities. Berkeley, CA: University of California Press.

Crompton, R., \& Lyonette, C. (2005). The new gender essentialism—Domestic and family “choices” and their relation to attitudes. The British Journal of Sociology, 56, 601-620.

Daly, M., \& Wilson, M. (1988). Homicide. New York, NY: Aldine de Gruyter.

Daly, M., Wilson, M., \& Weghorst, S. J. (1982). Male sexual jealousy. Ethology \& Sociobiology, 11-27.

Davidson, B., \& Sollie, D. L. (1987). Sex role orientation and marital adjustment. Social Behavior and Per.w/iality, 15, 59-69.

Dobash, R. E., \& Dobash, R. P. (1979). Violence against wives: A case against the patriarchy. New York, NY: Free Press.

Dobash, R. P., Dobash, R. E., Cavanagh, K., \& Lewis, R. (2000). Changing violent men. Thousand Oaks, CA: Sage.

Eagly \& Wood. (1991). Explaining sex differences in social behavior: A meta-analytic perspective. Personality and Social Psychology Bulletin, 17, 314.

Edwards, D. H., \& Kravitz, E. A. (1997). Serotonin, social status and aggression. Current Opinion in Neurobiology, 7, 812-819. 
Eleanor Emmons, M. (1966). Sex differences in intellectual functioning. In The development of sex differences (pp. 25-55). Stanford, Calif.: Stanford University Press.

Fredric, N. (2013, January 4). M.D. in Fighting Fear: Changing gender roles in marriage. (blog). Psychology Today. Retrieved September 6, 2013, from http://www.psychologytoday.com/blog/fighting-fear/201301/changing-gender-roles-in-marriage

Friedan, B. (1963). The feminist mystique. New York: Dell.

Grant, R. (1994). The cold war and the feminine mystique. In P. Beckman, F. d’Amico Bergin, and Garvey (Eds.), Women, gender and world politics. London: Bergin and Garvey.

Holly, J. (2012). Homicide Studies, 16, 332 originally published online 20 September 2012; doi: 10.1177/1088767912457169

Hyde, J. S. (2005). The gender similarities hypothesis. American Psychologist, 60, 581-892.

Ickes W. (1993). Traditional gender roles: Do they make, and then break, our relationships? Journal of Social Issues, 49, 71-85.

Johnson, H., Ollus, N., \& Nevala, S. (2008). Violence against women: An international perspective. New York, NY: Springer.

Kenneth, D., \& Nelwyn, M. (1996). Marriage and family: Change and continuity. Boston, Allyn \& Bacon, Incorporated.

Krahé, B., Bieneck, S., \& Moller, I. (2005). Understanding gender and intimate partner violence from an international perspective. Sex Roles, 52, 807-827.

Lackey, P. N. (1989). Adult attitudes about assignments of household chores to male and female children. Sex Roles, 20, $271-282$.

Mary, R., \& Albert, J. M. (2003). The cold war, feminism, and the ideation of the American family. Paper for presentation at Critical Management Studies Conference 3 “Cold War Stream”, University of Lancaster.

Meyerowitz, J. (1994). Not June Cleaver, women and gender in postwar America. Philadelphia: Temple University Press.

Poghosyan, A. (2012). The gender discourse and the gender policy perspectives in Armenia. Yerevan: Open Society Foundation.

Sanday, P. (1981). The socio-cultural context of rape: A cross-cultural study. Journal of Social Issues, 37, 5-27.

Sanday, P. (2008). Rape-prone versus rape free campus cultures. In M. Kimmel, and A. Aronson (Eds.), The gendered society reader (pp. 594-606). New York, NY: Oxford.

Skolnick, A. (1992). The intimate environment: Exploring marriage and the family (5th ed.). New York, NY: Harper Collins Publishers.

Sork, V. L. (1997). Quantitative genetics, feminism, and evolutionary theories of gender differences. In P. A. Gowaty (Ed.), Feminism and evolutionary biology (pp. 86-115). New York, NY: Chapman \& Hall.

Stark, E. (2007). Coercive control: The entrapment of women in personal life. New York, NY: Oxford.

Tancred-Sheriff, P., \& Jane Campbell, E. (1992). Room for women: A case study in the sociology of organizations. In J. Albert Mills and P. Tancred (Eds.), Gendering organizational analysis (pp. 31-45). Newbury Park: Sage.

Tang-Martinez, Z. (1997). The curious courtship of sociobiology and feminism: A case of irreconcilable differences. In P. A. Gowaty (Ed.), Feminism and evolutionary biology (pp. 116-150). New York, NY: Chapman \& Hall.

Venker, S. (2013). To be happy, we must admit women and men aren't “equal”. Published February 05, 2013, Fox News.com.

Walker, L. E. (1999). Battered woman syndrome (2nd ed.). New York, NY: Springer.

Weatherford, D. (1990). American women and World War II. New York: Facts on File.

Westbrook, R. B. (1990). I want a girl, just like the girl that married Harry James: American women and the problem of political obligation in World War II. American Quarterly, 542 (December), 587-614.

Wilson, M., \& Daly, M. (1985). Competitiveness, risk-taking and violence: The young male syndrome. Ethology \& Sociobiology, 6, 59-73.

World Health Organization. 2009. What do we mean by “sex” and “gender”?. Retrieved 2009-09-29. 